\title{
Detection and Diagnosis of Defect in GIS Based on $X$-ray Digital Imaging Technology ${ }^{\dagger}$
}

\author{
Tianhui Li ${ }^{1, *}$, Xianhai Pang ${ }^{1}$, Boyan Jia ${ }^{1}$, Yanwei Xia ${ }^{1}$, Siming Zeng ${ }^{1}$, Hongliang Liu ${ }^{1}$, \\ Hao Tian ${ }^{2}$, Fen Lin ${ }^{3}$ and Dan Wang 4 \\ 1 State Grid Hebei Electric Power Research Institute, State Grid Hebei Electric Power Co. Ltd., \\ Shijiazhuang 050021, China; 13582138125@163.com (X.P.); 13785186225@163.com (B.J.); \\ dyy_xiayw@he.sgcc.com.cn (Y.X.); dyy_zengsm@he.sgcc.com.cn (S.Z.); 13932126969@163.com (H.L.) \\ 2 Pinggao Group Co., Ltd., Pingdingshan 467001, China; zygys@pinggao.sgcc.com.cn \\ 3 Xiamen Jiahua Electrical Technology Co., Ltd., Fuzhou 350026, China; sales@jiahuatech.com \\ 4 Hebei Institute of Communications, Shijiazhuang 050021, China; 13931193026@139.com \\ * Correspondence: wdlth826@gmail.com; Tel.: +86-139-3119-3390 \\ $+\quad$ This paper is an extended version of the paper published in 2018 IEEE International Conference on High \\ Voltage Engineering and Application (ICHVE 2018), Athens, Greece, 10-13 September 2018, pp. 1-4.
}

Received: 19 November 2019; Accepted: 31 January 2020; Published: 4 February 2020

\begin{abstract}
For better application of X-ray digital imaging technology in defect detection in Gas Insulated Switchgear (GIS), it is essential to investigate the typical defect and establish the defect database, which has not been adequately performed in previous work. Systematic experimental research is also needed to accumulate data and experience. In this research, an experimental platform, including Computed Radiography (CR) imaging system and a GIS model, is built, and extensive tests of different kinds of typical defects are studied. The influence $\mathrm{X}$-ray irradiation on $\mathrm{SF}_{6}$ under different tube voltage levels is firstly examined, which proves that the withstand voltage of $\mathrm{SF}_{6}$ gas has not been affected and no dissociation has been found. Then, several kinds of defects are tested by X-ray digital imaging technology. The successful application examples of "visual" detection of defects further prove the practicability and validity of the X-ray digital imaging technique. Finally, the image database of typical defects inside of GIS is established and the defect risk is also analyzed in three levels, which would be useful for the defect severity diagnosis and risk assessment.
\end{abstract}

Keywords: X-ray; gas insulated switchgear (GIS); $\mathrm{SF}_{6}$; digital imaging technology

\section{Introduction}

Image processing technology has been extensively adopted in abnormal defect detection and diagnosis of electrical equipment because of the high accuracy and rich processing content [1,2]. Of varied methods, X-ray digital imaging technology can observe the internal structure abnormality of electrical equipment under live operation conditions by non-contact and nondestructive testing [3-6]. Gas insulated switchgear (GIS) is one of the important equipment in the power system. The national economy will be impacted once it breaks down. Therefore, rapid and accurate diagnosis of the internal defects takes great significance to the stable and reliable operation of the power grid [7-11].

The commonly used methods for GIS equipment detection, such as ultra-high frequency (UHF) PD detection, ultrasonic partial discharge (PD) detection, and gas decomposition detection of $\mathrm{SF}_{6}$, are proved to be effective and widely used to find the internal insulation defect [12-18]. However, these methods are all indirect detections that are not able to diagnose the physical defects accurately when no PD occurs [19-22]. This problem could be solved effectively by X-ray irradiation for the high reducibility $[23,24]$. X-ray digital imaging detection could visually discover the severity of defects, 
whether there is a partial discharge or not, which realizes the visual detection of GIS without power off and improves the diagnosis ability of the equipment operation status.

As the energy of the $\mathrm{X}$-ray is greater than most disturbances in the substation [25], X-ray imaging detection also has the advantages of interference immunity. However, it may also ionize the $\mathrm{SF}_{6}$ inside of GIS. If $\mathrm{SF}_{6}$ is decomposed due to X-ray irradiation, the internal insulation of GIS will be seriously reduced, even resulting in a safety accident. Thus, the ionization influence of $\mathrm{X}$-ray on $\mathrm{SF}_{6}$ needs to be further investigated, thus as to ensure the practicability of the method. As for the X-ray digital imaging detection, it is practical to identify and diagnose the internal defects in GIS. Since the defects on the actual site are variable, the establishment of a typical defect database becomes essential to guide severity diagnosis and risk assessment, which has not been considered adequately in previous work.

Based on the analysis above, an experimental platform including Computed Radiology (CR) imaging system and GIS model is built to test the irradiation on $\mathrm{SF}_{6}$ gas. The withstand voltage and composition of $\mathrm{SF}_{6}$ gas after irradiated by $\mathrm{X}$-ray under the different tube voltage levels are studied firstly. Next, an experimental arrangement is built, and the typical defects are detected by the X-ray digital imaging method, and the image results are obtained. Then, the defects under the different defect grades and their risk are analyzed in three levels. Accordingly, the image database of typical defects is established and generalized, while the X-ray detecting criterion for different defects is also given. The experimental results and the image database with the risk classification are original and would be useful for the practical application of X-ray digital imaging detection.

\section{X-ray Digital Imaging Detection Technology}

\subsection{Principle of X-ray Digital Imaging}

Figure 1a gives the schematic diagram of the $\mathrm{X}$-ray imaging detecting system [26-31]. The imaging plate that contains photosensitive phosphor will record the image signal once the $\mathrm{X}$-ray radiated from the emitter is perceived. Then, the image plate is sent to a digital converter in which it will be scanned by the laser beam. The image information released in the form of visible light would be captured and converted into a digital signal, and the image could be obtained subsequently through the calculation. Next, the CR reader scans the screen with a laser beam, and the laser energy can release captured electrons and cause the radiation of visible light. The released visible light will be captured and transferred into a digital bitstream and finally encoded into the digital image.

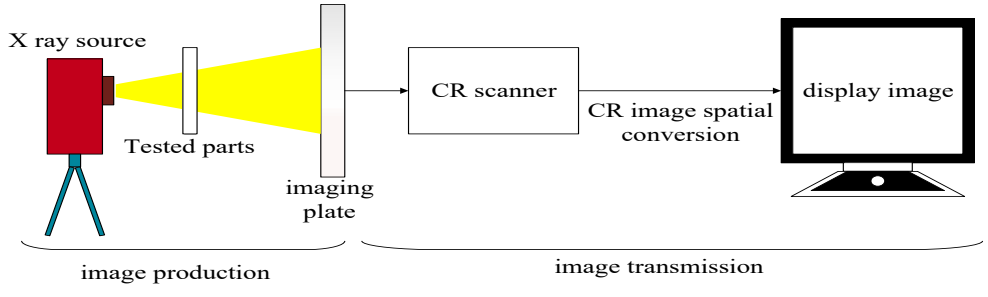

(a) the detecting system

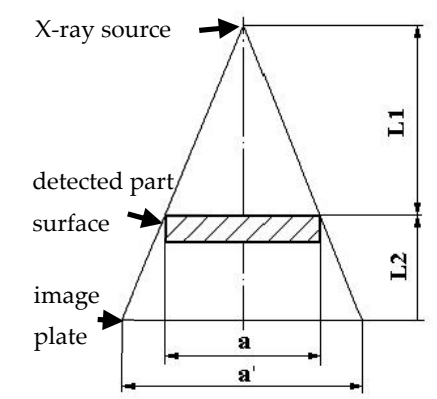

(b) principle of image enlargement

Figure 1. Schematic diagram of X-ray digital imaging detection.

Actually, it is impossible for the imaging plate to stick to the surface of the tested object inside of the GIS. Therefore, the digital image obtained on the imaging plate is inevitably enlarged, as Figure $1 \mathrm{~b}$ shows. The magnification depends on the distance from the X-ray source to the detected part surface $L_{1}$ and the distance from the detected part surface to the imaging plate $L_{2}$. Generally, $L_{1}$ is determined by the arrangement space of the $\mathrm{X}$-ray source in the field detection, while $L_{2}$ is determined by the size of the detected GIS equipment. 


\subsection{Experimental Platform Construction}

Considering the situation of the field application, the X-ray digital imaging system used for GIS contains the X-ray machine with a field moving bracket, the imaging plate, a CR scanner, a moving workstation with image processing and analysis software, the inspected GIS equipment, etc., which are shown in Figure 2a. This system can realize X-ray irradiation of high-risk parts in GIS, e.g., circuit breaker, disconnector, busbar connection, etc. Figure $2 \mathrm{~b}$ gives an example of testing the disconnector of $220 \mathrm{kV}$ GIS in the field. The information of internal structure is formed by the photosensitivity of the imaging plate, which is scanned using the laser digital scanning technology. The information gets transformed into digital image, then the investigation of the internal structure of GIS can be achieved.

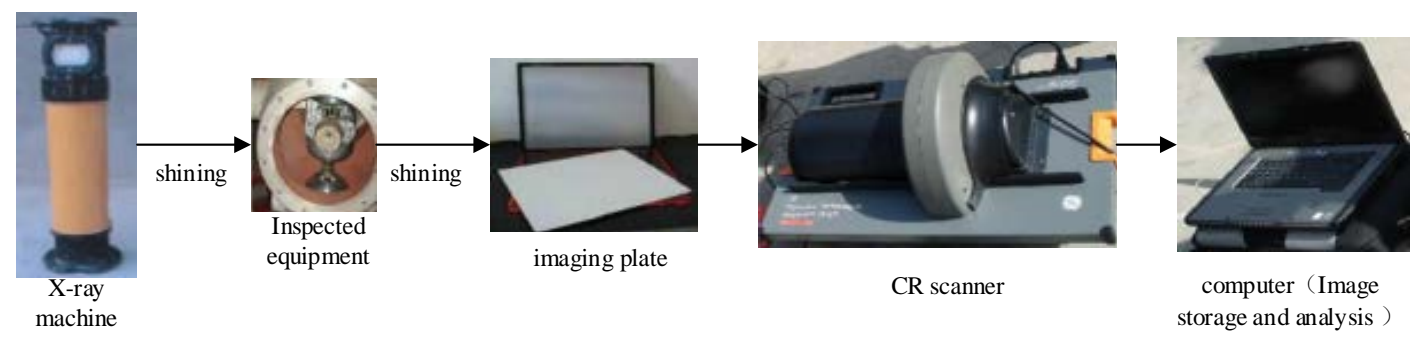

(a) the components and flow of the detecting system

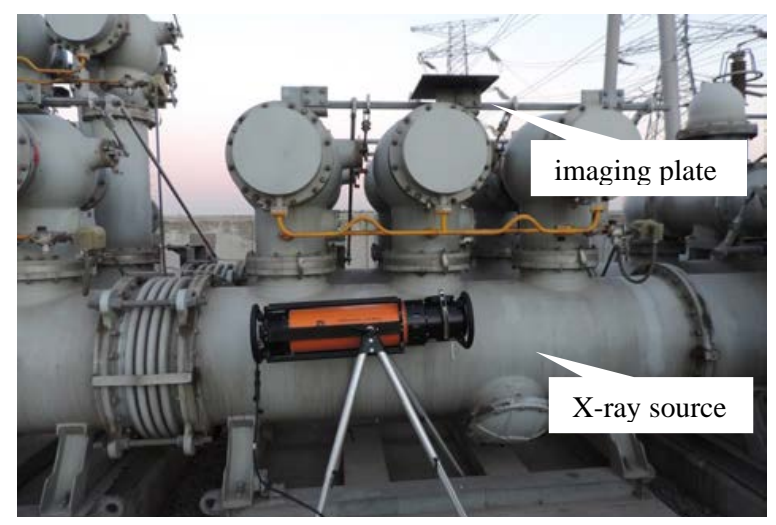

(b) a practical test case of $220 \mathrm{kV}$ GIS

Figure 2. X-ray digital imaging system and a practical test case.

\section{Influence of $\mathrm{X}$-ray Irradiation on $\mathrm{SF}_{6}$}

$\mathrm{X}$-ray radiation can cause material ionization, which will reduce the insulation of the material to some degree. Thus, the withstand voltage test and the $\mathrm{SF}_{6}$ dissociation test are taken thus as to examine the influence of $\mathrm{X}$-ray irradiation on $\mathrm{SF}_{6}$.

\subsection{The Withstand Voltage Test after X-ray Irradiation}

Figure 3 indicates the design of the test tooling filled with $0.4 \mathrm{MPa}$ of $\mathrm{SF}_{6}$ as well as the plate electrode with a diameter of $150 \mathrm{~mm}$ and the chamfer of $30 \mathrm{~mm}$, which are designed to get the stable value of the withstand voltage test. The gap between the electrodes is about $5 \mathrm{~mm}$. Figure 4 shows the complete photo of the test tooling. The bottom is equipped with a gas-pressure meter and a gas port. The breakdown test is carried out by applying a voltage at both ends of the test tooling.

Thus as to obtain systematic experimental comparison results, the breakdown test of the tooling was made firstly without any treatment, and the breakdown voltage before $\mathrm{X}$-ray irradiation was obtained 5 times. Subsequently, the test tooling was applied with $X$-ray irradiation under conditions that the tube voltage was set, respectively, as $100 \mathrm{kV} / 200 \mathrm{kV} / 300 \mathrm{kV}$, while the tube current was set as $5 \mathrm{~mA}$. The breakdown voltage test was made again after 5 minutes of irradiation, then the average breakdown voltage under each tube voltage level was obtained, which is shown in Figure 5. 


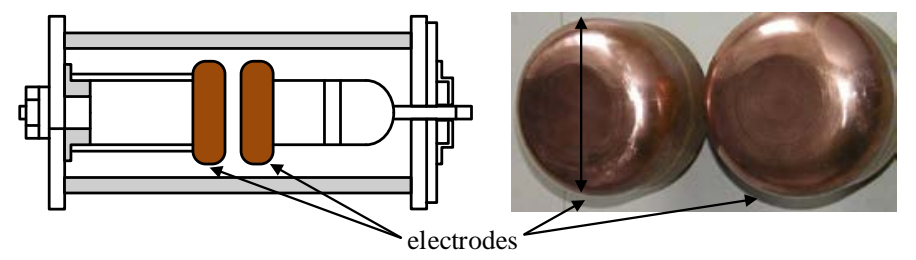

Figure 3. Drawing of the test tooling and pictures of plate electrodes.

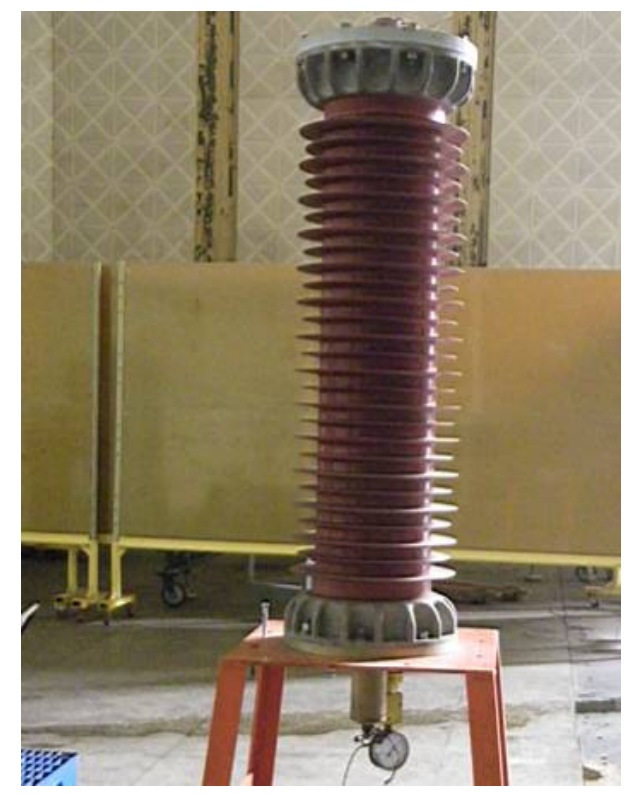

Figure 4. Complete photo of test tooling.

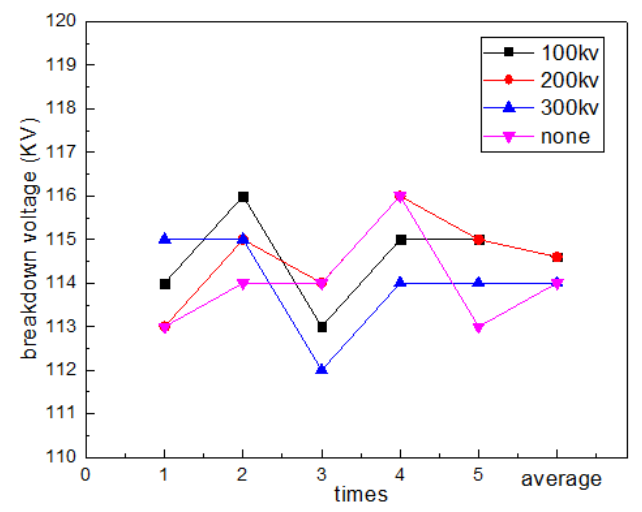

Figure 5. The results of the breakdown voltage.

After a comprehensive analysis of the results, it was found that the fluctuation of breakdown voltage, which was basically maintained as $114 \mathrm{kV}$, was not so much after X-ray irradiation. In consideration of the contingency of breakdown voltage itself, it was inferred that the breakdown voltage of $\mathrm{SF}_{6}$ remained broadly unchanged after the $\mathrm{X}$-ray irradiation. Actually, the X-ray irradiation was usually less than $3 \mathrm{~min}$ in the X-ray digital imaging detection of GIS. Thus, it can be regarded that there was no influence of $\mathrm{X}$-ray irradiation on the withstand voltage of $\mathrm{SF}_{6}$.

\section{2. $S F_{6}$ Dissociation Test after X-ray Irradiation}

To prevent the decomposition of $\mathrm{SF}_{6}$ in GIS caused by the X-ray imaging digital detection at the experiment site, the influence of the $\mathrm{X}$-ray irradiation on $\mathrm{SF}_{6}$ under various tube voltage levels was researched. The $\mathrm{SF}_{6}$ decomposition product detector was utilized in the test, and the accuracy of the 
equipment was $\pm 0.1 \mu \mathrm{L} / \mathrm{L}$. Thus as to conduct the comparison under several cases conveniently, the composition of the gas under each voltage level was initially measured and recorded by using a spectrometer. Then, the X-ray irradiation was conducted under the corresponding tube voltage for 1/3/5/7 min. Afterward, the composition of the gas was measured and recorded again. Next, the gas was replaced, and the irradiation was conducted under the other tube voltage levels. Table 1 and Figure 6 display the results.

Table 1. Gas composition results under different voltages.

\begin{tabular}{|c|c|c|c|c|c|c|}
\hline Tube Voltage & Gas Composition & New Gas & $1 \mathrm{~min}$ & $3 \mathrm{~min}$ & $5 \mathrm{~min}$ & $7 \mathrm{~min}$ \\
\hline \multirow{4}{*}{$100 \mathrm{kV}$} & $\mathrm{CF}_{4}(\mathrm{uL} / \mathrm{L})$ & 21.2 & 21.2 & 21.4 & 21.3 & 21.2 \\
\hline & $\mathrm{H}_{2} \mathrm{~S}(\mathrm{uL} / \mathrm{L})$ & 0 & 0 & 0 & 0 & 0 \\
\hline & $\mathrm{SO}_{2}(\mathrm{uL} / \mathrm{L})$ & 0 & 0 & 0 & 0 & 0 \\
\hline & $\mathrm{SF}_{6}(\%)$ & 99.99 & 99.99 & 99.99 & 99.99 & 99.99 \\
\hline \multirow{4}{*}{$200 \mathrm{kV}$} & $\mathrm{CF}_{4}(\mathrm{uL} / \mathrm{L})$ & 21.3 & 21.4 & 21.3 & 21.2 & 21.3 \\
\hline & $\mathrm{H}_{2} \mathrm{~S}(\mathrm{uL} / \mathrm{L})$ & 0 & 0 & 0 & 0 & 0 \\
\hline & $\mathrm{SO}_{2}(\mathrm{uL} / \mathrm{L})$ & 0 & 0 & 0 & 0 & 0 \\
\hline & $\mathrm{SF}_{6}(\%)$ & 99.99 & 99.99 & 99.99 & 99.99 & 99.99 \\
\hline \multirow{4}{*}{$300 \mathrm{kV}$} & $\mathrm{CF}_{4}(\mathrm{uL} / \mathrm{L})$ & 21.2 & 21.4 & 21.3 & 21.3 & 21.2 \\
\hline & $\mathrm{H}_{2} \mathrm{~S}(\mathrm{uL} / \mathrm{L})$ & 0 & 0 & 0 & 0 & 0 \\
\hline & $\mathrm{SO}_{2}(\mathrm{uL} / \mathrm{L})$ & 0 & 0 & 0 & 0 & 0 \\
\hline & $\mathrm{SF}_{6}(\%)$ & 99.99 & 99.99 & 99.99 & 99.99 & 99.99 \\
\hline
\end{tabular}

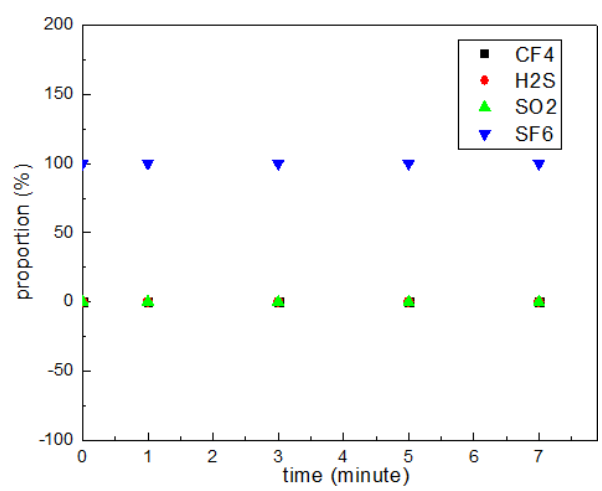

(a) $100 \mathrm{kV}$

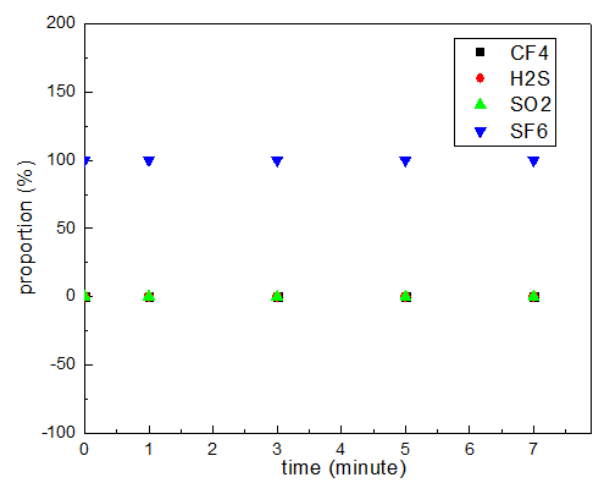

(b) $200 \mathrm{kV}$

Figure 6. Cont. 


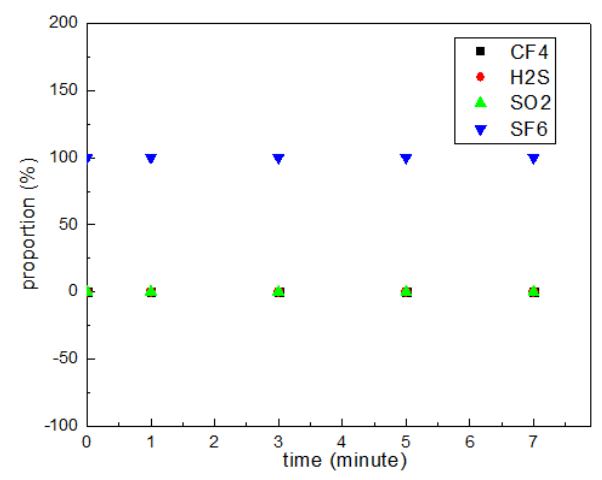

(c) $300 \mathrm{kV}$

Figure 6. Gas composition results under different voltages.

Through the comparison of the results, it demonstrated that the content $\mathrm{CF}_{4}$, which is an inherent ingredient of the new $\mathrm{SF}_{6}$ gas, was extremely low. And the concentration of $\mathrm{CF}_{4}$ did not increase along with the duration time and the tube voltage level of the X-ray irradiation. Moreover, $\mathrm{H}_{2} \mathrm{~S}$ and $\mathrm{SO}_{2}$ were both not founded from first to last. It can be known from the test that no dissociation of $\mathrm{SF}_{6}$ was found after X-ray irradiation for 7 min under $300 \mathrm{kV}$ tube voltage.

\section{Experimental Test of X-ray Digital Imaging Detection for GIS}

Since the above analyses proved that $\mathrm{X}$-ray irradiation had no influence on the withstand voltage and the decomposition of $\mathrm{SF}_{6}$, several kinds of defects were tested by $\mathrm{X}$-ray digital imaging detection. The experimental model filled with $\mathrm{SF}_{6}$ of $0.4 \mathrm{MPa}$ was set according to a $110 \mathrm{kV}$ GIS. Figure 7 shows a test example of detecting free particles inside from the bottom of the tank. This section gives successful application examples of "visual" detection, and an image database of typical defects inside of GIS is established.

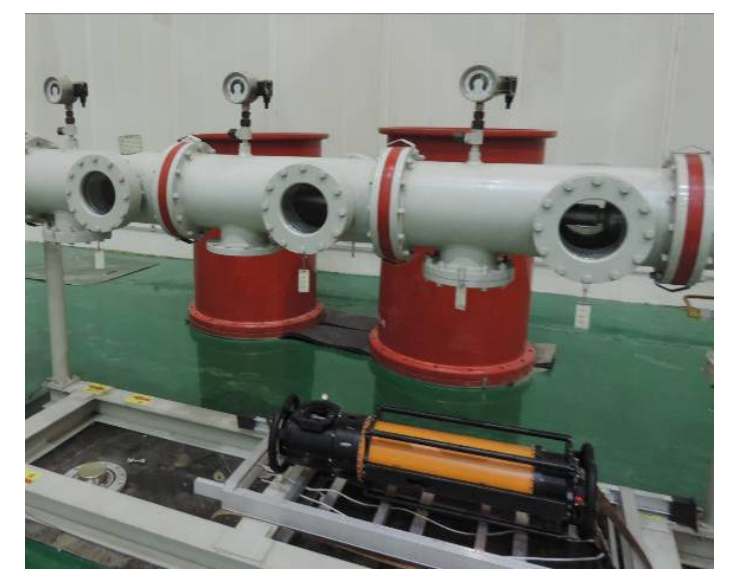

Figure 7. The experimental model.

\subsection{Free Metal Particles}

In order to simulate the X-ray digital imaging atlas of metal-free particles in GIS, the typical X-ray atlas of columnar metal particles was tested. The copper particles with diameters of $1.3 \mathrm{~mm}$ and $0.11 \mathrm{~mm}$ were specially made. The lengths of metal particles $L$ were made in three grades as $1 \mathrm{~mm}$, $3 \mathrm{~mm}$, and $5 \mathrm{~mm}$. The X-ray digital imaging of the copper-free particles is shown below.

It can be seen that the metal particles with the two kinds of diameters in the GIS tank can be clearly imaged, and the particles in Figure 8 were proportional to their length. However, the metal particles with a diameter of $0.11 \mathrm{~mm}$ and a length of $1 \mathrm{~mm}$ were not clearly imaged. By comparing the length of 
columnar particles of $3 \mathrm{~mm}$ and $5 \mathrm{~mm}$, it showed that the length of metal particles with a diameter of $0.11 \mathrm{~mm}$ was still in the corresponding proportion. It is proved that the free metal particle can be well detected by $\mathrm{X}$-ray digital imaging technology.

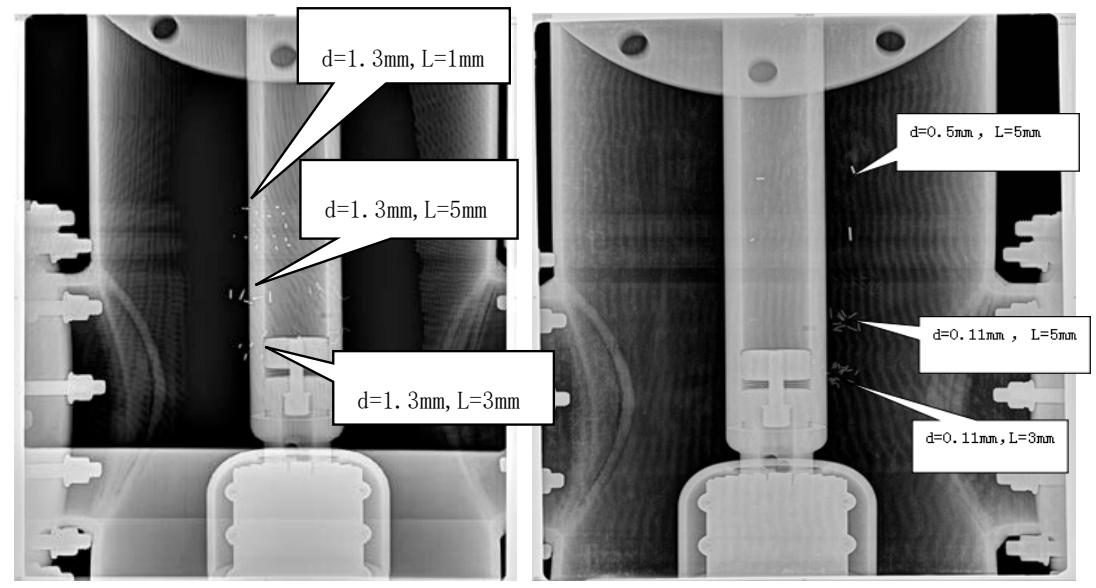

(a) $d=1.3 \mathrm{~mm}$

(b) $d=0.11 \mathrm{~mm}$

Figure 8. Free metal particle.

\subsection{Flaky Free Particles}

Metal and rubber gaskets are usually used during site installation, which may be missing in the GIS tank. In order to survey the X-ray digital imaging of flaky free particles caused by gaskets, a typical $\mathrm{X}$-ray atlas of both metallic and non-metallic flaky particles are tested. The thickness of metal (iron) flaky particle in Figure 9 was $0.8 \mathrm{~mm}$, and the area was not less than $1 \mathrm{~cm}^{2}$, and the non-metallic flaky particles in Figure 10 were made by flaky rubber.
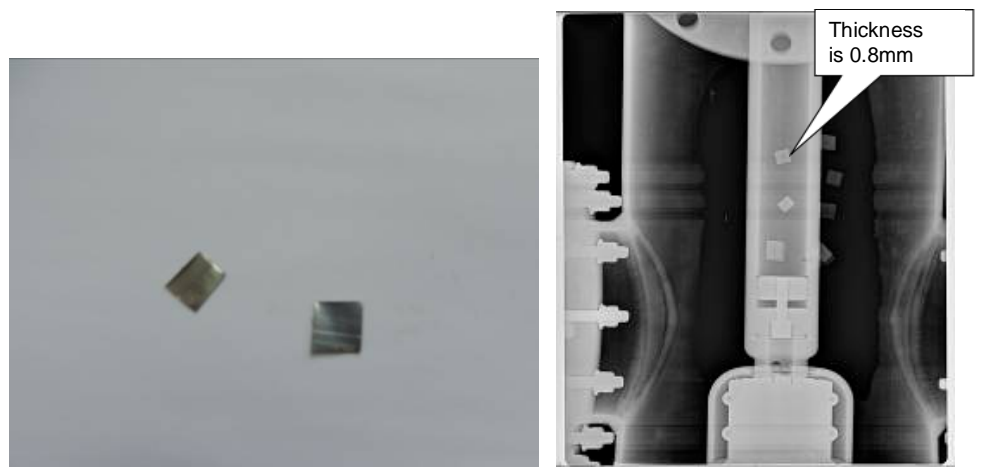

Figure 9. Metallic flaky particle.

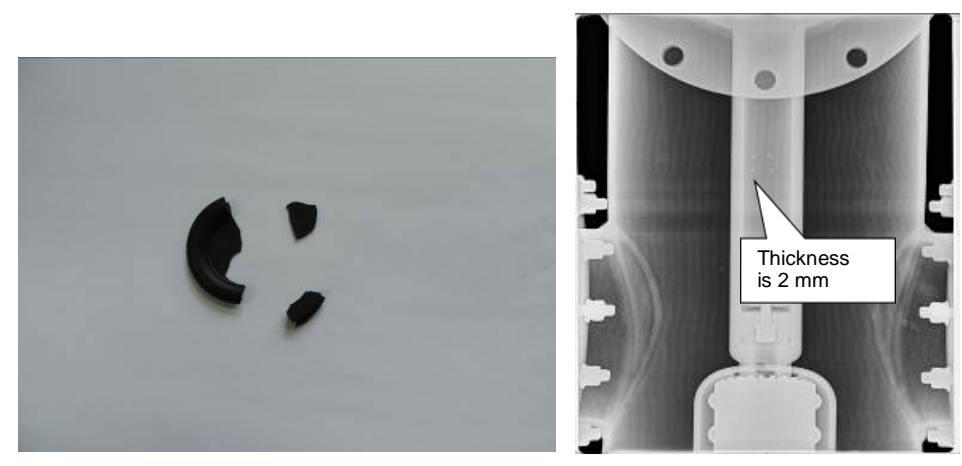

Figure 10. Non-metallic flaky particle. 
Figure 9 shows that the image of iron-free particles is clear, and the non-metallic flaky particle could also be distinguished in Figure 10. Considering the thickness of the gaskets used in site installation process of GIS is generally over $1 \mathrm{~mm}$, the X-ray digital imaging technology can be used to detect the flaky particle omitted inside the tank clearly.

\subsection{Adsorbents and Cover}

In order to absorb moisture in $\mathrm{SF}_{6}$ gas, adsorbents were installed in the adsorbent cover inside GIS. The adsorbent cover was generally made of stainless steel. Some manufacturers use plastic covers to reduce costs. However, the thermal expansion coefficient of plastic material is much larger than that of metal material. When the temperature changes greatly, the degree of thermal expansion and contraction of GIS metal tank and plastic adsorbent cover varies greatly, which makes the cover age and damage easily. Facts have proved that if the adsorbent cover breaks down and the adsorbent drops off, it will cause the internal discharge fault in the GIS. It is necessary to detect and distinguish the cover material, then it could be possible to eliminate defects of the plastic cover. Figure 11 gives the covers with two different materials.

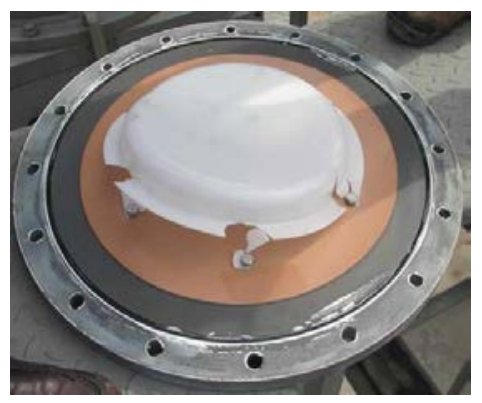

(a) plastic cover

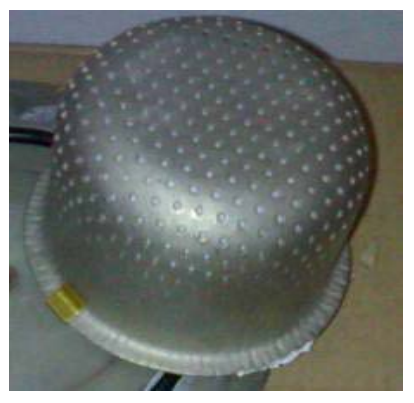

(b) metal cover

Figure 11. The covers with two different materials.

Because there is no partial discharge before the cover is damaged, it could not be effectively detected by live detection methods such as UHF and ultrasound. Nevertheless, X-ray digital imaging technology could be used to detect the adsorbent cover in GIS in order to avoid equipment failure. The perspective images of the adsorbent covers made of different materials are given in Figure 12.

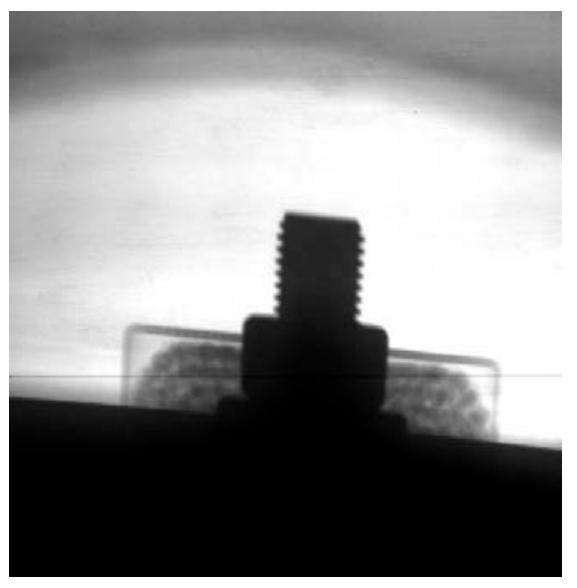

(a) plastic cover

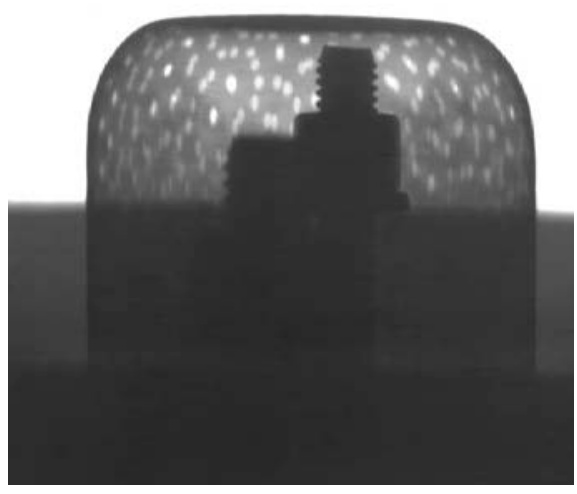

(b) metal cover

Figure 12. The images of adsorbent cover with different materials.

It can be seen that the outline and mesh of the plastic adsorbent cover are not clear, while the adsorbent (molecular sieve particles) and the corners of the cover can be seen clearly. This is mainly 
due to the thin material and small density of the plastic adsorbent cover. And the outline of the cover is not clear compared with the negative.

For the metal adsorbent cover, the outline and mesh are clear, but the adsorbent is not obvious. It is because the adsorbent cover is thicker, and the stainless-steel density is larger, which increases the difficulty of X-ray penetration and the contrast of the adsorbent cover. As a result of casting technology, the cover has no corners and edges, which also reduces the electric field strength of the adsorbent cover.

According to the features above, the material of the adsorbent cover in GIS can be clearly distinguished and hidden troubles can be investigated in the visualization detection by $\mathrm{X}$-ray digital imaging technology. The major problem that the adsorbent cover defect is difficult to identify and judge effectively could be solved, and this detection method provides strong technical support for condition-based maintenance of GIS equipment. Moreover, the equipment power outage and blindly disassembly inspection is also avoided.

\subsection{The Loosened Metal Screw}

The bolts are fixed in every structural part of the GIS equipment, and the loosening of bolts has become one of the important defects. The loosening of bolts can lead to bad alignment and contact, resulting in contact surface overheating and floating metal discharge and so on.

The normal and loosened metal screws are shown in Figure 13. The bolt loosening defects in GIS are visible under X-ray digital imaging. The slightly loosened bolt can continue live operation in a short time, but the gasket has loosened and may lead to floating discharge. After long-term operation, it will endanger the safety of the equipment.
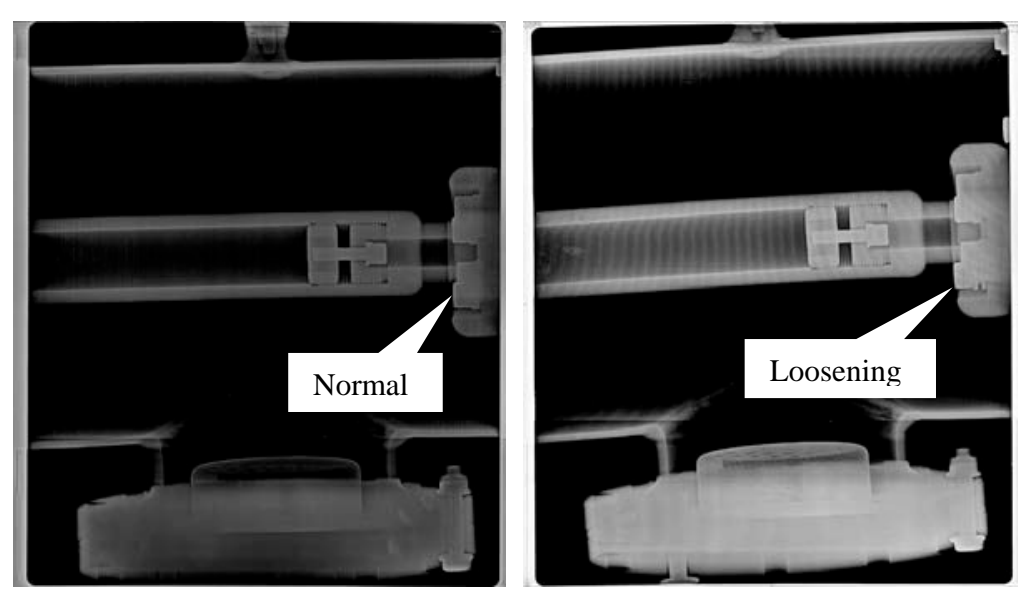

Figure 13. The normal and loosened metal screws.

\section{Defect Database Establishment and Defect Risk Assessment}

Taking the defects founded in actual X-ray digital imaging detection as examples, this section established atlases of different defect grades, etc., the general, serious, and critical defect. The results further prove the practicability and validity of the X-ray digital imaging technique and would be useful for the defect severity diagnosis.

\subsection{General Defect}

\subsubsection{False Welding without Gas Leaking}

The compressed tank needs to be welded at the joint. Because the GIS tank is thick, it is easy to produce false welding. The tank may not leak gas after welding for a short time. However, after long time operation, especially when welding parts are corroded and exposed to the air directly, it will cause gas leakage and pose a threat to the safety of the equipment. Figure 14 gives an example. 

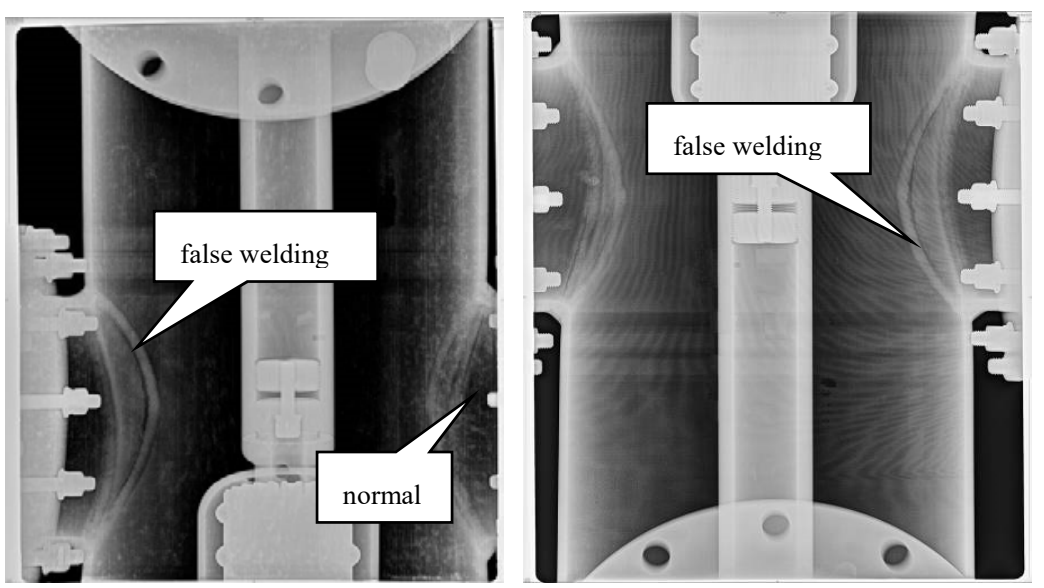

Figure 14. The normal and loosened metal screws.

For GIS with false welding joints or lines in X-ray digital imaging atlas, if welding parts are found by on-site appearance inspection to be exposed in air due to the tank corrosion, it is recommended to evaluate them as an attentive state. And for non-corroded wedding joints, it can be regarded as a normal state.

\subsubsection{Foreign Bodies in the Particle Trap}

The particle trap inside the GIS is used to capture foreign bodies in metal or non-metallic impurities. Because the foreign bodies in the particle trap does not pose a threat to the electric field, the equipment can still be operated. However, if the foreign bodies are too large or accumulated for a long time, it may pose a security threat as shown in Figure 15.
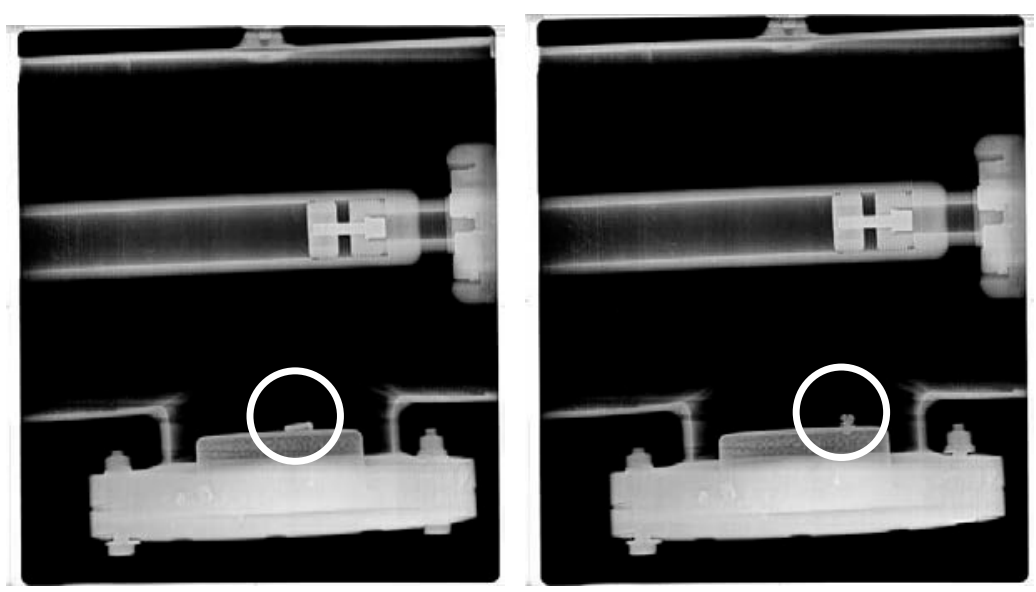

Figure 15. Foreign bodies in the particle trap.

Generally, metal or non-metallic foreign bodies in the particle trap can be identified as general defects. If there are more than three foreign bodies or the height is higher than one-third of the particle trap, it is recommended to evaluate the state of attention.

\subsubsection{Slight Loosening of Metal Screw in the Grading Shield}

As the examples show in Figure 13, slight loosening of the screw (less than two threads) can be judged as a general defect. If the bolt or screw is only slightly loosened within two threads and still in the hood with no PD, it would be evaluated as a state of attention. 


\subsubsection{Metal Tip in the Grading Shield}

The grading shield is a part of GIS equipment to balance voltage and reduce the electric field. Generally, the metal tip in the grading shield will not pose a threat to the operation of the equipment. However, the protruding tip, especially the tip burr, which is easy to fall off, may cause partial discharge. And it can lead to breakdown failure of GIS in serious cases. Figure 16 gives an example.
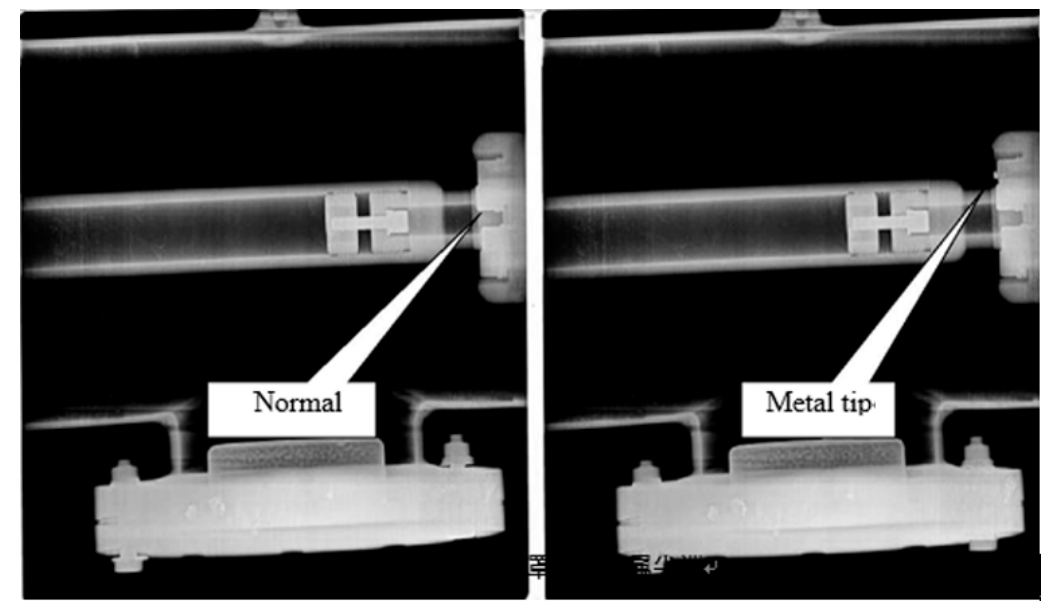

Figure 16. Metal tip in the grading shield.

Thus, the defect identification basis in X-ray digital imaging is firstly determined. The sharp burrs, which are easy to fall off, can be judged as a general defect, and it is suggested to be evaluated as a state of attention. If there is no burr that is easy to fall off and only the inner corner bolt in the grading shield, it should not be judged as a general defect.

\subsubsection{Adsorbent Cover Made of High Strength Rigid Plastics}

If the hard-plastic adsorbent cover (need to be verified with the manufacturer) can be clearly identified in the X-ray digital imaging atlas, it can be regarded as a general defect. For those covers used less than 5 years, it can be evaluated as a normal state. Otherwise, it should be evaluated as an attention state.

\subsection{Serious Defect}

\subsubsection{Oblivious Loosening of Metal Screw in the Grading Shield and without PD}

If the bolt or screw is loosened more than two threads, but no partial discharge occurs, it is recommended to be evaluated as a serious defect and abnormal state.

\subsubsection{A Long Tip without PD}

Long metal tips (such as contact fingers) in the grading shield will change and crack the electric field distribution. Serious cases will result in partial discharge and even equipment failure.

Thus, if a long metal tip in the grading shield (which has exceeded or will exceed the grading shield) can be clearly seen, it can be judged as a serious defect and evaluated as an abnormal state. Figure 17 shows a typical atlas. 


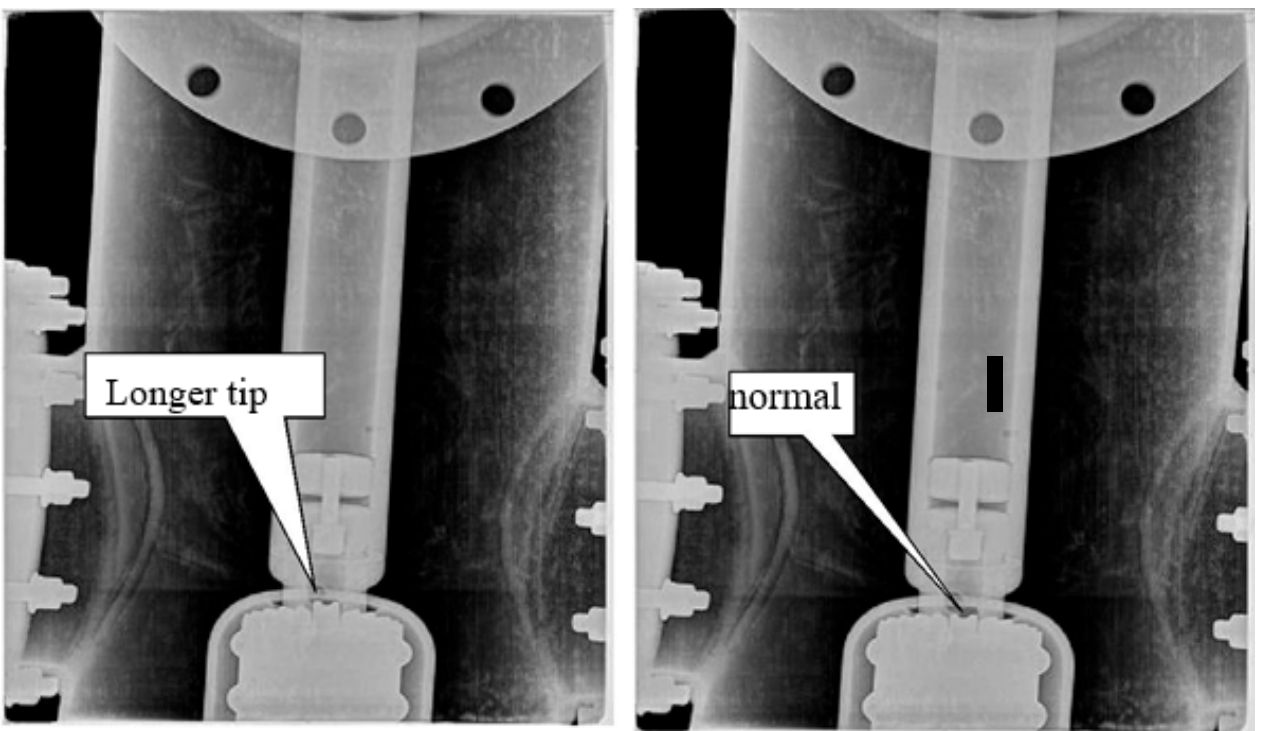

Figure 17. The long metal tip in the grading shield with no partial discharge.

\subsubsection{Adsorbent Cover Made of General Plastics}

If the general-plastic adsorbent cover (need to be verified with the manufacturer) can be determined as Figure 18 indicated, it is recommended to be evaluated as a serious defect. For the post-commissioning equipment, it can be evaluated as an abnormal state.

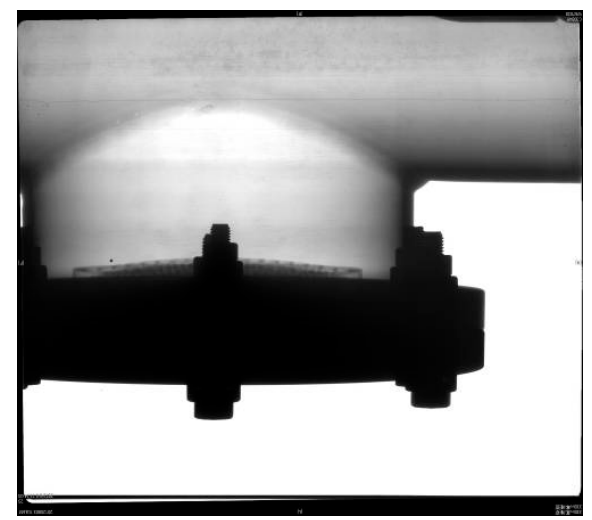

Figure 18. Adsorbent cover made of general plastics.

\subsubsection{No Absorbent and Normal Moisture}

After the equipment is put into operation, the moisture content of $\mathrm{SF}_{6}$ in the tank will naturally increase due to the difference of water pressure inside and outside the tank and the accumulation of water on the surface of the components inside the tank. The excessive moisture content will reduce the insulation performance of internal insulation materials to a certain extent, especially for solid insulation materials. In order to avoid the impact of excessive moisture on the safe and stable operation of the equipment, the adsorbent will be placed inside the GIS, which has the effect of absorbing water and reducing the moisture in $\mathrm{SF}_{6}$. However, sometimes the factory or site installation personnel do not strictly implement the process flow, which would cause the forgotten of adsorbents installation, like Figure 19 shows.

If the missing of absorbent is found in the X-ray digital imaging atlas, while the moisture has been inspected to be not exceeding the standard, it can be judged as a serious defect and abnormal state. 

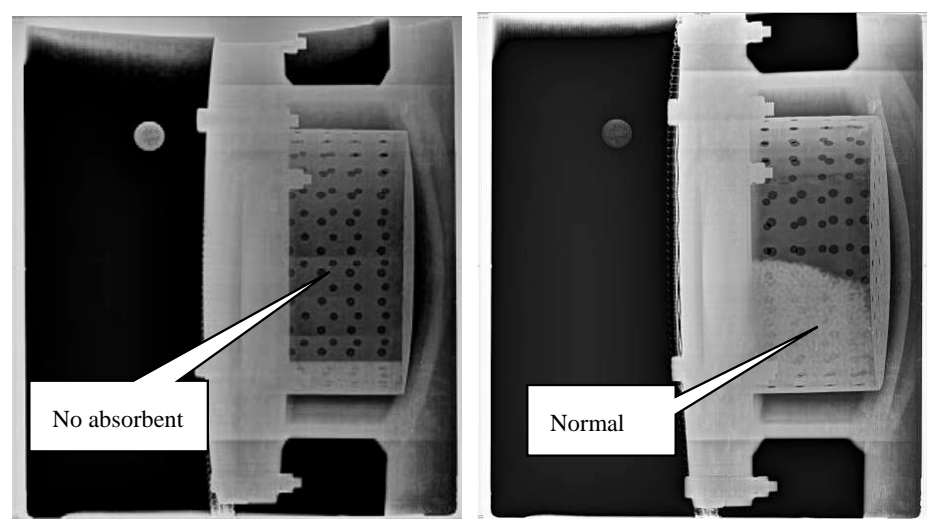

Figure 19. Abnormal and normal absorbent.

\subsubsection{Partial Spring Missing}

Due to poor manufacturing and installation of GIS, the spring of the disconnector plug-in contact head is missing. When the spring is missing, the contact pressure will be reduced and the contact resistance will be increased, which can lead to bad contact alignment and bad contact, resulting in contact overheating, suspension discharge, and other defects. In serious cases, it can lead to the failure of GIS equipment.

Missing of partial spring in disconnector but without partial discharge detected, it could be evaluated as an abnormal state. Even if the measured circuit resistance is qualified, it should still be regarded as a serious defect.

\subsection{Critical Defect}

\subsubsection{Foreign Bodies in the Tank}

The presence of metal or non-metal foreign bodies in the tank is the main reason for the failure of GIS. The metal-free particles in the tank, which is the main cause of the breakdown failure, are the most harmful to the equipment.

Thus, if foreign bodies are found in the tank (not in the particle trap or grading shield), it is recommended to be evaluated as a critical defect. For those found in the particle trap or grading shield, it can be judged according to the relevant content of general and serious defects.

\subsubsection{The Metal Screw Loosened Obviously and Have PD}

If the screw is loosened apparently (more than two threads) and partial discharge characteristic is detected, it consequently can be judged as a crisis defect and recommended to be evaluated as a serious state. Figure 20 shows the $\mathrm{X}$-ray detection atlas of examples.
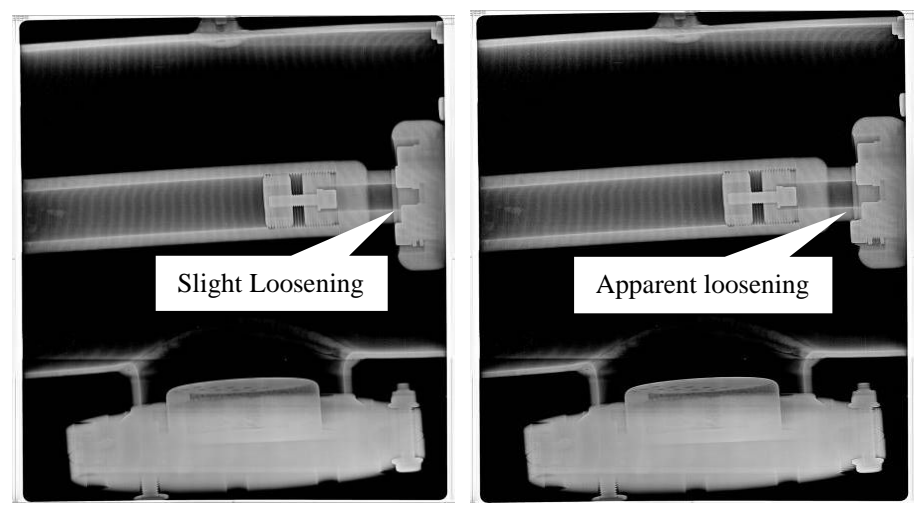

Figure 20. The obviously loosened metal screws in the grading shield with partial discharge. 


\subsubsection{Damage of Plastic Adsorbent Cover}

The broken adsorbent cover or the overflowing adsorbent caused by seasonal variation or sudden temperature changing will crack the electric field distribution, which will result in equipment failure in serious cases. Thus, this kind of defect can be evaluated as a critical defect.

\subsubsection{Missing Key Components}

In extreme cases, some key parts of the equipment, such as a conductive rod, grading shield, are missing or partially missing because of the poor quality of the installation process. Figure 21 shows two examples of a conductive rod missing and partial contactor missing, which have been successfully found in the substation field by X-ray digital imaging detection.

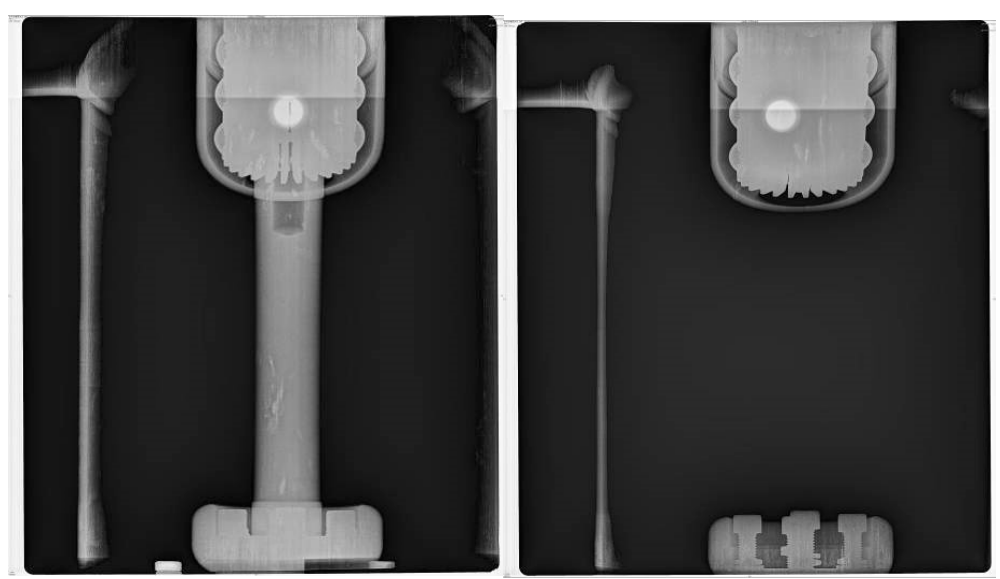

(a) Conductive rod missing of lightning arrester
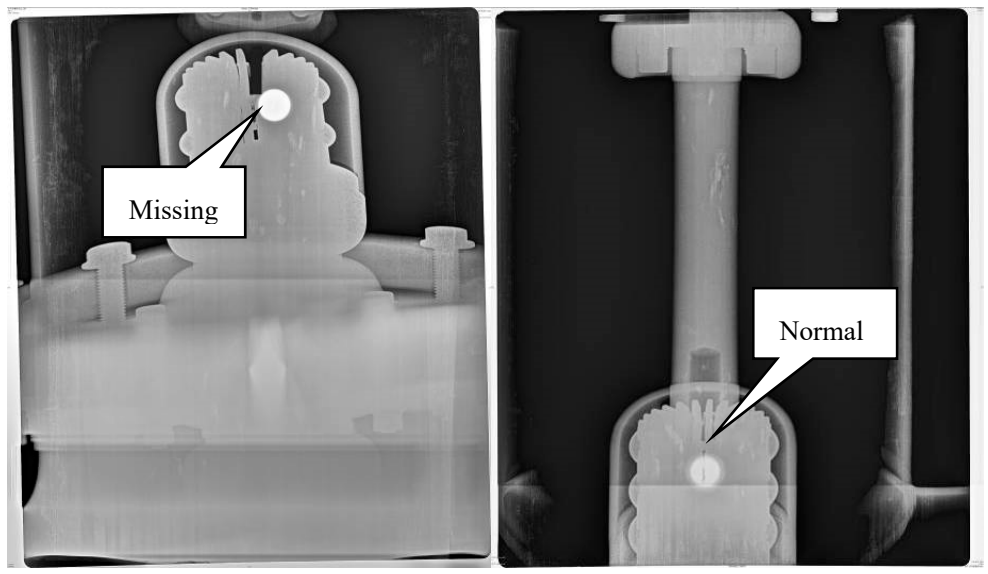

(b) Partial contactor missing of the disconnector

Figure 21. Examples of key components missing.

This kind of defect will pose a great threat to the safe and stable operation of the equipment, and even directly lead to failure. As a result, the missing key components found in X-ray digital imaging can be judged as critical defects, and it is recommended to be evaluated as a serious state.

\subsubsection{No Absorbent and Excessive Moisture}

As previous content mentioned, the excessive moisture which will reduce the insulation performance of the internal insulation materials is a serious threat to equipment safety. If the missing of absorbent is found while the moisture exceeded the standard, it can be judged as a critical defect and evaluated as a serious state. 


\subsection{Typical Defect Database of X-ray Visualization and Risk Assessment}

According to the analysis above, the different types of defects are delimited into three grades in Table 2, thus as to provide a helpful reference for the judgment and identification of the typical defects in GIS. (A: general grade, B: serious grade, C: critical grade).

Table 2. Risk assessment of typical defects in gas insulated switchgear (GIS).

\begin{tabular}{|c|c|c|c|c|c|}
\hline \multicolumn{3}{|c|}{ Defect Grade } & $\mathbf{A}$ & B & $\mathrm{C}$ \\
\hline \multirow{7}{*}{$\begin{array}{l}\text { Defect } \\
\text { type }\end{array}$} & \multicolumn{2}{|c|}{ Tank wall } & $\begin{array}{l}\text { false welding } \\
\text { without leaking }\end{array}$ & 1 & 1 \\
\hline & \multicolumn{2}{|c|}{ Foreign bodies } & $\begin{array}{l}\text { single and small in } \\
\text { particle trap }\end{array}$ & $\begin{array}{l}\text { more and higher in } \\
\text { particle trap }\end{array}$ & in the tank \\
\hline & \multirow{2}{*}{$\begin{array}{l}\text { Grading } \\
\text { shield }\end{array}$} & Metal tip & $\begin{array}{l}\text { subsistent and air } \\
\text { tight }\end{array}$ & longer with no PD & longer with PD * \\
\hline & & Metal screw & slight loosening & $\begin{array}{l}\text { apparent loosening } \\
\text { with no PD }\end{array}$ & $\begin{array}{c}\text { apparent loosening } \\
\text { with PD * }\end{array}$ \\
\hline & \multicolumn{2}{|c|}{ Adsorbent cover } & $\begin{array}{l}\text { strength rigid } \\
\text { plastics }\end{array}$ & $\begin{array}{l}\text { general material } \\
\text { plastic }\end{array}$ & breakage \\
\hline & \multicolumn{2}{|c|}{ Tank moisture value } & 1 & $\begin{array}{l}\text { no absorbent and } \\
\text { normal moisture }\end{array}$ & $\begin{array}{l}\text { no absorbent with } \\
\text { exceeded moisture }\end{array}$ \\
\hline & \multicolumn{2}{|c|}{ Component missing } & 1 & $\begin{array}{c}\text { spring of } \\
\text { disconnector }\end{array}$ & key parts missing \\
\hline
\end{tabular}

* the typical PRPD patterns can refer to [8,12-15].

\section{Discussion}

\subsection{Personnel Protection}

What needs to be noticed is that the $\mathrm{X}$-ray is a kind of ionizing radiation with very short wavelengths and harmful for living things. When X-ray irradiates an organism for a long time, cells can be inhibited, destroyed, or even died. The operation environment of GIS is in the substation and there are no animals or plants, only operators. Therefore, it is particularly important to take effective protection measures in X-ray field detection to ensure the safety of the operators.

Different countries have regulations on the protection area. For example, the area with a dose equivalent rate above $15 \mu \mathrm{Sv} / \mathrm{h}$ is defined as the control area according to the standard GBZ 117-2015 in China [32]. In previous research, the radiation field, as well as the relationship between radiation dose rate and the protection distance, have been studied through the comparison and analysis of theoretical calculation and experimental detection $[23,33]$. The results show that: For the maximum tube voltage and tube current under $300 \mathrm{kV}$ and $5 \mathrm{~mA}$, respectively, in the actual detection, the air protection distance for the operator is less than $57 \mathrm{~m}$ at the angle between $135^{\circ}$ and $225^{\circ}$ in the direction of the X-ray beam. Moreover, operating in a building and setting a lead sheet are both tested to be effective for the radiation protection of the operator and public.

\subsection{The Radiation Time and the Effect}

As mentioned before, the X-ray irradiation in the actual detection of GIS is generally in a short time of less than $3 \mathrm{~min}$. Thus, the tests in Section 3 were carried out up to $7 \mathrm{~min}$, which is already exceeded the general irradiation time and long enough to investigate the influence in engineering application. In fact, if the effect of X-ray digital imaging detection is not so well within a short time, expanding the time could also be invalid commonly. Some other measures have to be taken in these cases, such as increasing tube voltage. 
For the long term of X-ray irradiations, the influence to $\mathrm{SF}_{6}$ and the metal tank of GIS may be different. This scientific question is not covered in this paper and will be considered in future research.

\subsection{Limitations}

The detection based on the X-ray also has limitations. This method is highly dependent on the detection position and angle to obtain the best detection imaging. However, the ideal detecting position may not be achieved as a result of the limitation of the narrow space of GIS, especially for the equipment part of phase $B$, which is in the middle between phases A and C. The miniaturized testing equipment is useful in this case.

Testing personnel experience is also an important factor, which can reduce the number of repetitive tests. The image database of typical defects established in this paper synthesizes a great deal of experimental experience, including the common defect location, and it will be helpful for the practicing engineers.

\section{Conclusions}

The detection and diagnosis of defects in GIS based on X-ray digital imaging technology are profoundly investigated in this research, helping to improve and guide the actual application. The conclusions are summarized below.

1. The experimental platform, including CR digital imaging system and the GIS model, is set up and the test tooling, which can be filled with $\mathrm{SF}_{6}$ in a certain pressure, is designed. The withstand voltage test and dissociation test of $\mathrm{SF}_{6}$ after $\mathrm{X}$-ray irradiation under different tube voltages are launched, which indicates that the decomposition characteristics and withstand voltage of $\mathrm{SF}_{6}$ gas are unaffected.

2. The common defects, including different kinds of free particles, the adsorbent cover with different materials and the loosened metal screw are detected by the X-ray digital imaging method and the images results are obtained. The lower parameters' limit of the clearness of free particles is found to be the diameter of $0.11 \mathrm{~mm}$ and length of $3 \mathrm{~mm}$. The material of adsorbent cover in GIS can be clearly distinguished, and the loosened metal screw in GIS is visible under X-ray digital imaging.

3. Plenty of examples of the defects, which are divided into three grades, are analyzed, while the corresponding criteria of X-ray detection under different defects are also given. Accordingly, the image database of typical defects is established and generalized, which provides a reference for the defect severity diagnosis.

This research further proves the effectiveness of X-ray digital imaging technology in the visual detection of GIS internal defects. In the future, more experiments for different kinds of defects are expected to be performed thus as to enrich the database.

Author Contributions: T.L., B.J., H.T., and F.L. designed the experimental platform; H.L., Y.X. and S.Z. processed the images; T.L., X.P., and D.W. made the results analyzation; T.L. and D.W. wrote the paper. All authors have read and agreed to the published version of the manuscript.

Funding: This work was supported by the Science and Technology Project of State Grid Hebei Electric Power Supply CO., LTD. (kj2011-014, kj2012-114 and TSS2017-07).

Conflicts of Interest: The authors declare no conflict of interest.

\section{References}

1. Asiegbu, G.O.; Haidar, A.M.A.; Hawari, K. A review of defect detection on electrical components using image processing technology. In Proceedings of the Fourth International Conference on Signal and Image Processing 2012 (ICSIP 2012), New Delhi, India, 11 January 2013; Springer: Berlin/Heidelberg, Germany, 2013; pp. 247-255. 
2. Van Metter, R.; Yorkston, J. Factors influencing image quality in digital radiographic system. In Medical Imaging 2001: Physics of Medical Imaging; The International Society for Optics and Photonics: Bellingham, WA, USA, 2001; Volume 4320, pp. 244-255.

3. Granfors, P.R.; Aufrichtig, R. DQE (f) of an amorphous silicon flat panel x-ray detector: Detector parameter influences and measurement methodology. In Medical Imaging 2001: Physics of Medical Imaging; The International Society for Optics and Photonics: Bellingham, WA, USA, 2000; Volume 3977, pp. 2-12.

4. Aufrichtig, R.; Su, Y. Measurement of the noise power spectrum in digital X-ray detectors. In Medical Imaging 2001: Physics of Medical Imaging; The International Society for Optics and Photonics: Bellingham, WA, USA, 2001; Volume 4320, pp. 362-372.

5. Kengyelics, S.M.; Cowen, A.R.; Davies, A.G. Image quality evaluation of a direct digital radiography detector operating in a UK radiology department. In Medical Imaging 2001: Physics of Medical Imaging; The International Society for Optics and Photonics: Bellingham, WA, USA, 1999; Volume 3659, pp. 24-35.

6. Jain, A.; Dubuisson, M. Segmentation of X-ray and C-scan images of fiber reinforced composite materials. Patern Recognit. 1992, 25, 257-270. [CrossRef]

7. Istad, M.; Runde, M. Thirty-six years of service experience with a national population of gas-insulated substations. IEEE Trans. Power Deliv. 2010, 25, 2448-2454. [CrossRef]

8. Jiang, T.Y.; Li, J.; Zheng, Y.B.; Sun, C.X. Improved bagging algorithm for pattern recognition in UHF signals of partial discharges. Energies 2011, 4, 1087-1101. [CrossRef]

9. Tang, J.; Zhou, J.B.; Zhang, X.X.; Liu, F. A Transformer partial discharge measurement system based on fluorescent fiber. Energies 2012, 5, 1490-1502. [CrossRef]

10. Li, T.; Rong, M.; Wang, X.; Pan, J. Experimental investigation on propagation characteristics of PD radiated UHF signal in actual $252 \mathrm{kV}$ GIS. Energies 2017, 10, 942. [CrossRef]

11. Xin, L. Modern High Voltage Switchgear Technology, 2nd ed.; China Machine Press: Beijing, China, 2011.

12. Okabe, S.; Ueta, G.; Hama, H.; Ito, T.; Hikita, M.; Okubo, H. New aspects of UHF PD diagnostics on gas-insulated systems. IEEE Trans. Dielectr. Electr. Insul. 2014, 21, 2245-2258. [CrossRef]

13. Judd, M.D.; Farish, O.; Hampton, B.F. The excitation of UHF signals by partial discharges in GIS. IEEE Trans. Dielectr. Electr. Insul. 1996, 3, 213-228. [CrossRef]

14. Metwally, I.A. Status review on partial discharge measurement techniques in gas-insulated switchgear/lines. Electr. Power Syst. Res. 2004, 69, 25-36. [CrossRef]

15. Koo, J.Y.; Jung, S.Y.; Ryu, C.H.; Lee, S.W.; Lee, B.W. Identification of insulation defects in gas-insulated switchgear by chaotic analysis of partial discharge. IET Sci. Meas. Technol. 2010, 4, 115-124. [CrossRef]

16. Hoshino, T.; Maruyama, S.; Nojima, K.; Hanai, M. A unique sensitivity verification combined with real-time PD identification method. IEEE Trans. Power Del. 2005, 20, 1890-1896. [CrossRef]

17. Tolkachev, A.A.; Levitan, B.A.; Solovjev, G.K.; Veytsel, V.V.; Farber, V.E. A megawatt power millimeter-wave phased-array radar. IEEE AES Syst. Mag. 2000, 15, 25-31. [CrossRef]

18. Tang, J.; Liu, F.; Meng, Q.; Zhang, X.; Tao, J. Partial discharge recognition through an analysis of SF6 decomposition products part 2, feature extraction and decision tree-based pattern recognition. IEEE Trans. Dielectr. Electr. Insul. 2012, 19, 37-44. [CrossRef]

19. Li, T.H.; Wang, X.H.; Zheng, C.; Liu, D.X.; Rong, M.Z. Investigation on the placement effect of UHF sensor and propagation characteristics of PD-induced electromagnetic wave in GIS based on FDTD method. IEEE Trans. Dielectr. Electr. Insul. 2014, 21, 1015-1025. [CrossRef]

20. Xie, Q.; Wang, Y.; Li, T.; Bian, X.; Zhang, H.; Xu, Y. Application of signal sparse decomposition in the detection of partial discharge by ultrasonic array method. IEEE Trans. Dielectr. Electr. Insul. 2015, 22, 2031-2040. [CrossRef]

21. Hikita, M. Recent technology development on partial discharge measurements in diagnosis for GIS, transformers, cables and inverter-fed motors. In Proceedings of the 14th Asian Conference on Electrical Discharge, Bandung, Indonesia, 23-25 November 2008; pp. 1-8.

22. Min, C.; Urano, K.; You-Cheng, L.; Jinno, A. Application of combined PD sensor for GIS PD detection and condition monitoring. In Proceedings of the 2008 International Conference on Condition Monitoring and Diagnosis, Beijing, China, 21-24 April 2008; pp. 456-460.

23. Yihuan, Z.; Jiachen, W.; Jian, X.; Ren, X. Measurement of radiation field and safe area in X-ray detection for GIS. High Volt. Eng. 2018, 44, 1699-1705. 
24. Yihuan, Z.; Jiachen, W.; Yanan, W.; Li, Z. X-ray detection for foreign body defect in GIS. High Volt. Eng. 2019, $55,41-46$.

25. Nagi, Ł.; Zmarzły, D.; Boczar, T.; Frącz, P. Detection of high-energy ionizing radiation generated by electrical discharges in oil. IEEE Trans. Dielectr. Electr. Insul. 2016, 23, 2036-2041. [CrossRef]

26. Koch, A.; Macherel, J.M.; Wirth, T.; de Groot, P.M.; Ducourant, T.; Couder, D.; Calais, E. Detective quantum efficiency of an X-ray image intensifier chain as a benchmark for amorphous silicon flat panel detectors. In Medical Imaging 2001: Physics of Medical Imaging; The International Society for Optics and Photonics: Bellingham, WA, USA, 2001; Volume 4320, pp. 115-120.

27. Hong, Y.; Jie, W.; Xianping, Z.; Yi, M.; Lei, C. The perspective detection of the X-ray digital radiography for the electrical equipment. In Proceedings of the International Conference on High Voltage Engineering and Application, Shanghai, China, 17-20 September 2012; pp. 591-599.

28. Strecker, H. Scatter imaging of aluminum castings using an X-ray fan beam and a pinpole camera. Mater. Eval. 1982, 40, 1050-1056.

29. Lashkia, V. Defect detection in X-ray images using fuzzy reasoning. Image Vision Comput. 2001, 19, 261-269. [CrossRef]

30. Huanqing, X.; Junpeng, M.; Chengliang, W.A.N.G. Study on digital X-ray imaging technology for detecting typical defects in GIS equipment. J. Grid Technol. 2017, 41, 1697-1702.

31. Pang, X.; Qi, Y.; Li, X.; Wu, H.; Jing, H.; Xie, Q. Research on defect pattern recognition of GIS equipment based on X-ray digital imaging technology. In Proceedings of the IEEE International Conference on High Voltage Engineering and Application (ICHVE 2018), Athens, Greece, 10-13 September 2018; pp. 1-4.

32. Deng, D.; Li, H.; Hou, C.; Wan, L.; Lu, F.; Feng, L.; Song, G. Requirement for Radiological Protection in Industrial X-ray Radiography; GBZ117_2015; China Standard Press: Beijing, China, 2015.

33. Pang, X.; Jing, H.; Zhang, L. X-ray field detection applications and protection measures for GIS equipment. Shaanxi Electric Power 2015, 43, 92-96.

(C) 2020 by the authors. Licensee MDPI, Basel, Switzerland. This article is an open access article distributed under the terms and conditions of the Creative Commons Attribution (CC BY) license (http://creativecommons.org/licenses/by/4.0/). 